\title{
Use of an Amplatzer Device for Endoscopic Closure of a Large Bronchopleural Fistula following Lobectomy for a Stage I Squamous Cell Carcinoma
}

\author{
$\begin{array}{llll}\text { A. Ottevaere } & \text { H. Slabbynck } & \text { P. Vermeersch } & \text { P. Rogiers } \\ & \text { C }\end{array}$

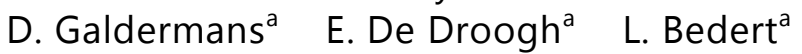 \\ Departments of ${ }^{\mathrm{a}}$ Pneumology, ${ }^{\mathrm{b}}$ Cardiology, and ${ }^{\mathrm{C}}$ Intensive Care Medicine, ZNA \\ Middelheim, Antwerp, Belgium
}

\section{Key Words}

Bronchopleural fistula - Amplatzer device - Endoscopic closure $\cdot$ Lung cancer

\begin{abstract}
Bronchopleural fistulas can occur as a rare but severe complication after pulmonary resection. Established guidelines for the proper treatment of patients with bronchopleural fistulas do not exist. Apart from attempts to close the fistula, emphasis is placed on preventive measures, early treatment with antibiotics, drainage of the empyema and aggressive nutritional and rehabilitative support. For inoperable patients, endoscopic procedures are the only therapeutic option. Unfortunately, large $(>8 \mathrm{~mm})$ or central bronchopleural fistulas are usually not suitable for such endoscopic management. Recently, some groups have published a few case reports about a novel technique for the endobronchial closure of bronchopleural fistulas, using an Amplatzer device, originally designed for transcatheter closure of cardiac septal defects. We applied the same technique as a life-saving treatment in a ventilated patient who was considered inoperable due to a high oxygen need. The operation was successful. The patient could be weaned from ventilation and was eventually discharged from the hospital to a rehabilitation facility several weeks after the insertion of the device. Until now, endoscopic techniques have only been useful for the treatment of small, peripheral, bronchopleural fistulas and even then only as a bridge to surgery in high-risk surgical patients. In this case report, we demonstrate that the use of an Amplatzer device can expand the importance of endoscopic techniques in the treatment of bronchopleural fistulas. An Amplatzer device, for endobronchial closure, can
\end{abstract}


Ottevaere et al.: Use of an Amplatzer Device for Endoscopic Closure of a Large Bronchopleural Fistula following Lobectomy for a Stage I Squamous Cell Carcinoma

indeed be administered for large and central bronchopleural fistulas. Moreover, it can be considered as a definite alternative to surgery in inoperable patients.

(c) 2013 S. Karger AG, Basel

\section{Introduction}

Bronchopleural fistulas can occur as a rare but severe complication after pulmonary resection. The incidence rate ranges from 4.5 to $20 \%$ after pneumonectomy and is $0.5 \%$ after lobectomy [1]. The risk of developing a bronchopleural fistula is greater when surgery is performed for a malignancy and even more when radiation or chemotherapy is given [1-3].

Until now, the management of bronchopleural fistulas remains a difficult issue. There are no established guidelines, nor is there a consensus on how to approach the problem. Besides attempts to close the fistula, preventive measures, early treatment with antibiotics, drainage of the empyema and aggressive nutritional and rehabilitative support are of major importance. Yet, when a patient is inoperable, only endoscopic procedures with the application of sealants can be used to close the fistula. Unfortunately, large ( $>8 \mathrm{~mm}$ ) or central bronchopleural fistulas are usually not eligible for such endoscopic treatment [4].

Recently, Fruchter et al. and Kramer et al. have described several successful cases where a novel technique has been used to close bronchopleural fistulas. They used an Amplatzer septal occluder device, which has originally been developed for the endovascular closure of cardiac septal defects [5-7]. We present an inoperable patient with a large bronchopleural fistula, arisen after lobectomy for a stage I squamous cell carcinoma. In the absence of other therapeutic options, we decided to apply the novel endoscopic technique, using the Amplatzer septal occluder device, in an attempt to close the fistula.

\section{Case Report}

We report on a 68-year-old woman with a history of a diffuse, large, B-cell, non-Hodgkin lymphoma of the thyroid and stomach (stage IV B). She underwent surgery (resection of a thyroidal mass) and was treated with chemotherapy after which complete remission was achieved. At that time, she also underwent tracheal stenting because of recurring aspiration related to a fistula (postoperative) between the oesophagus and the trachea.

Five years later, she was diagnosed with a squamous lung carcinoma in the right lower lobe - stage IA. She smoked one package of cigarettes a day. A lobectomy was performed and the initial postoperative course was favourable. However, 5 days later, she started suffering from marked dyspnoea. During clinical examination, we noted a subcutaneous emphysema. Developing respiratory insufficiency with extensive bilateral infiltrates visible on chest X-ray prompted intubation and mechanical ventilation. Bronchoscopy revealed a large (approximately $10 \mathrm{~mm}$ in diameter) bronchopleural fistula in the middle of the right bronchial stump.

Initial treatment with antibiotics, chest tube drainage and parenteral feeding failed. Since the patient had a high oxygen need, she was considered inoperable. Due to the size and central location of the fistula, conventional endoscopic treatment did not seem an option either. The tracheal stent was removed and tracheotomy was performed. Unfortunately, the patient remained septic and repeated bronchoscopy was needed to remove extensive, sticky, endobronchial secretions.

Since no other therapeutic option was available, a 10-mm Amplatzer septal occluder device was eventually placed through the fistula. This device, originally developed for the 
endovascular closure of cardiac septal defects, consists of two expandable disks, made of nitinol wire mesh, connected by a central waist. The device can be compressed inside a catheter. By placing the catheter inside the defect and then releasing the device from the delivering sheath, the disks can anchor the device on either side of the defect.

In our case, a guide wire was introduced through the fistula under direct bronchoscopic visualization. Subsequently, a delivery sheath was pushed over the guide wire beyond the defect. The Amplatzer device was then placed by pulling the delivering sheath back gradually. The distal disk was first extruded and pulled back against the distal side of the defect. The central waist filled the actual defect. Then, the second disk was placed on the proximal side of the defect. Once positioned correctly, the device was released by unscrewing the attached cable.

The procedure was successful with almost complete closure of the fistula, but because of a small persistent air leak, BioGlue surgical adhesive was applied after a couple of days to obtain a complete seal of the bronchopleural fistula (fig. 1). Within the next week, the patient could be weaned from ventilation. Bronchoscopic reassessment showed granulation tissue developing progressively around the device which caused further closure of the fistula. The patient was eventually discharged from the hospital to a rehabilitation facility several weeks after the insertion of the device. Follow-up 6 months after the insertion of the Amplatzer device was reassuring. There were no remaining symptoms and CT thorax showed a good position of the device and full expansion of the lung tissue without any remaining pleural cavity (fig. 2).

\section{Discussion}

Bronchopleural fistulas can occur after lobectomy or pneumonectomy. Although rare, this complication is associated with high morbidity and mortality rates. Its management remains a difficult matter because no scientific evidence for optimal treatment is available. Reported interventions are all based on small (often retrospective) series or individual cases.

Our patient suffered from a large bronchopleural fistula, following right lower lobectomy and was considered inoperable. In the absence of any other options, a novel endoscopic technique, using an Amplatzer septal occluder device, was successfully applied resulting in the closure of the bronchopleural fistula. This allowed subsequent weaning from ventilation and discharge from the hospital. The family of the patient was informed of the fact that an off-label use of the device was being performed.

Up until now, endoscopic techniques have been considered to be only useful for the treatment of small, peripheral, bronchopleural fistulas, most often as a bridge to surgery in high-risk surgical patients. In this case report we illustrate that the use of an Amplatzer septal occluder device can expand the importance of endoscopic techniques in the treatment of bronchopleural fistulas. In this particular case, the endobronchial application of an Amplatzer septal occluder device - an experimental procedure which was the only possible option in this very weak, inoperable, ventilated patient - led to the closure of a very large, central, bronchopleural fistula and furthermore provided a definite cure of the fistula. Studies exploring the use of this technique as an alternative to surgery even in operable patients might be of interest. This case furthermore illustrates the potential use of devices designed for other purposes in other disciplines and highlights the advantages of close collaboration between different specialities, e.g. interventional pulmonologists and cardiologists as in our patient. 
Ottevaere et al.: Use of an Amplatzer Device for Endoscopic Closure of a Large Bronchopleural Fistula following Lobectomy for a Stage I Squamous Cell Carcinoma

\section{Disclosure Statement}

None of the authors has any conflicts of interest regarding the content of this article.

\section{References}

1 Cerfolio RJ: The incidence, etiology and prevention of postresectional bronchopleural fistula. Semin Thorac Cardiovasc Surg 2001;13:3-7.

-2 Sirbu H, Busch T, Aleksic I, Schreiner W, Oster O, Dalichau H: Bronchopleural fistula in the surgery of nonsmall cell lung cancer: incidence, risk factors and management. Ann Thorac Cardiovasc Surg 2001;7:330336.

3 Sonobe M, Nakagawa M, Ichinose M, Ikegami N, Nagasawa M, Shindo T: Analysis of risk factors in bronchopleural fistula after pulmonary resection for primary lung cancer. Eur J Cardiothor Surg 2000;18:519-523.

4 Lois M, Noppen M: Bronchopleural fistulas: an overview of the problem with special focus on endoscopic management. Chest 2005;128:3955-3956.

5 Kramer MR, Peled N, Shitrit D, Atar E, Saute M, Shlomi D, Amital A, Bruckheimer E: Use of Amplatzer device for endobronchial closure of bronchopleural fistulas. Chest 2008;133:1481-1484.

-6 Fruchter O, Kramer MR, Dagan T, Raviv Y, Abdel-Rahman N, Saute M, Bruckheimer E: Endobronchial closure of bronchopleural fistulae using Amplatzer devices: our experience and literature review. Chest 2011;139:682-687.

7 Fruchter O, Bruckheimer E, Raviv Y, Rosengarten D, Saute M, Kramer MR: Endobronchial closure of bronchopleural fistulas with Amplatzer vascular plug. Eur J Cardiothorac Surg 2012;41:46-49.
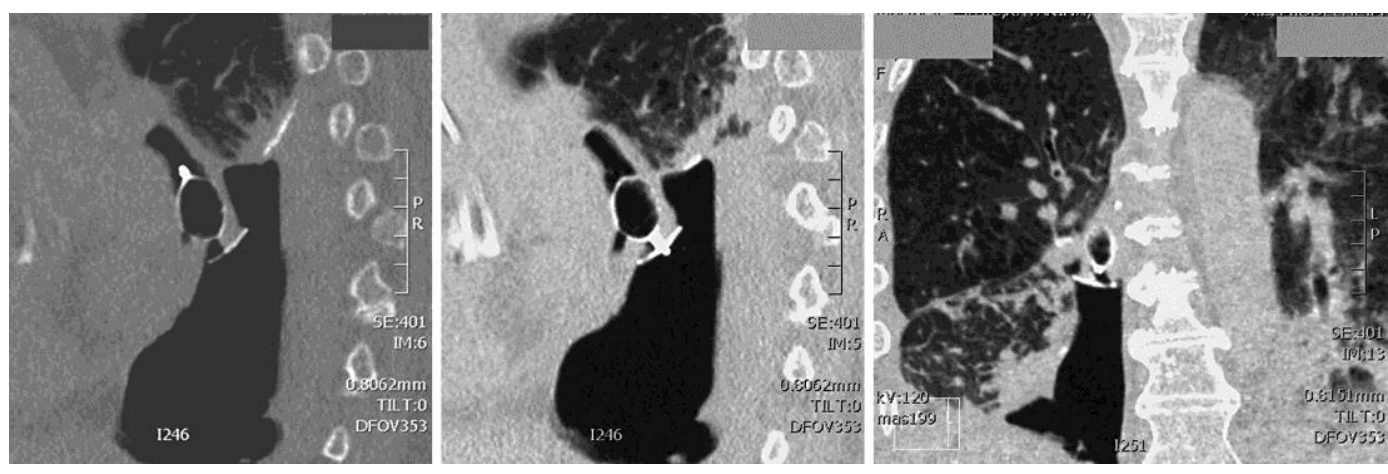

Fig. 1. CT images immediately after the insertion of the Amplatzer device show a correct position of the device, although the proximal disk is not completely expanded. A pleural cavity remains. 


\section{Case Reports in Oncology}

\begin{tabular}{l|l}
\hline Case Rep Oncol 2013;6:550-554 & \multicolumn{2}{l}{$\begin{array}{l}\text { C 2013 S. Karger AG, Basel } \\
\text { www.karger.com/cro }\end{array}$} \\
\hline DOI: 10.1159/000356444 &
\end{tabular}

Ottevaere et al.: Use of an Amplatzer Device for Endoscopic Closure of a Large Bronchopleural Fistula following Lobectomy for a Stage I Squamous Cell Carcinoma
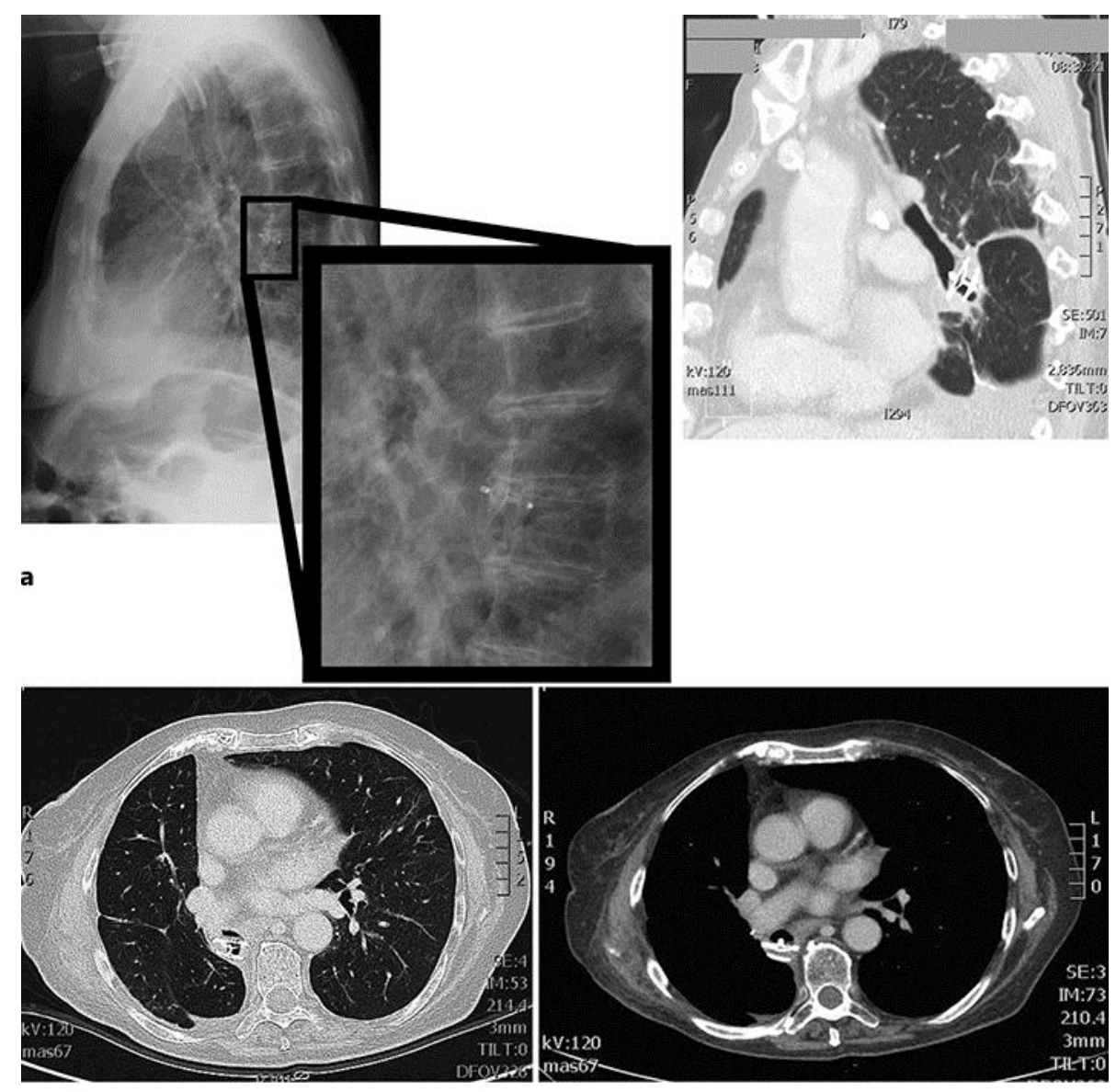

b

Fig. 2. a Thorax RX and CT image 6 months after the insertion of the Amplatzer device show a good position of the device with a complete expansion of the proximal disk and a full expansion of the lung tissue without any remaining pleural cavity. b CT images 6 months after the insertion of the Amplatzer device show a good position of the device with a complete expansion of the proximal disk and a full expansion of the lung tissue without any remaining pleural cavity. 